\title{
The significance of particle size of long-range transported mineral dust
}

Jan-Berend W. Stuut ${ }^{1,2}$ and Maarten A. Prins ${ }^{3}$

\begin{abstract}
The physical properties of mineral-dust particles turn out to be more important than hitherto recognized; their composition, radiative properties, and fertilizing and ballasting potential fluctuate on various spatial and temporal scales. Especially the impact of large dust particles is often underestimated.
\end{abstract}

The role of aeolian dust for the radiation balance of the Earth is size-dependent. Dust has a direct cooling effect when small particles $(<2 \mu \mathrm{m})$ elevated into the high atmosphere block incoming sunlight (e.g. Claquin et al. 2003), but it can also act like a greenhouse gas when larger particles (> $10 \mu \mathrm{m}$ ) remaining in the lower atmosphere absorb and re-emit energy reflected from the Earth's surface (e.g. Otto et al. 2007). Therefore, to account for the climatic effect of mineral dust it is critical to have a good understanding of the size distribution of suspended particles in space and time.

However, until now, the scientific community has not considered the fact that dust particles suspended in the atmosphere and transported over large distances ( $>1000$ 's km) can easily be of sizes $>10 \mu \mathrm{m}$. Specific set-up of air-monitoring programs, which are designed to measure air quality for human health studies and follow the guidelines of the World Health Organization (WHO), which do not consider particles larger than $10 \mu \mathrm{m}$. For this reason, these large dust particles are often simply not measured. As a consequence, they do not show up in the records and therefore seem non-existent.

\section{Grain size sorting during transport}

The particle-size distribution of mineral dust is not only a function of lateral but also vertical transport distance (e.g. Torres-Padrón et al. 2002). This observation had already been put into a conceptual model by Pye and Zhou (1989; Fig. 1) As wind is a very size-selective transport mechanism, the sediments it had carried typically a well-sorted particle-size distribution, which gradually gets finer from proximal to distal deposition sites. This fact has been used in numerous paleo-environmental studies to both determine source-to-sink changes in the particle size of aeolian dust (e.g. Sarnthein et al. 1981; Prins and Vriend 2007) and to quantify accumulation rates of aeolian dust (e.g. Prins and Weltje 1999; Moreno et al. 2005). Obviously, at proximal locations (where aeolian dust is deposited relatively close to its source), particles are coarser grained and mass accumulation rates are larger than at more distal locations (where aeolian dust is deposited relatively far from its source). This observation was first prominently described by Sarnthein et al. (1981; Fig. 2).

\section{Evidence for large aeolian particles}

Despite the availability of these conceptual models and many grain-size related studies, there are still many unresolved questions related to the physical properties of wind-blown particles, particularly their particle size and shape. Most of the mineral-dust particles that are suspended in air and collected further than $100 \mathrm{~km}$ away from their source are smaller than 20 $\mu \mathrm{m}$ (e.g. Middleton et al. 2001, and references therein). This particle-size constraint can be explained by the physical laws of entrainment and settling velocities (e.g. Gillette 1979). However, various aeolian-dust records from loess and marine sediments contain considerable amounts of coarse-silt and fine-sand grains, i.e. particles well above the theoretical $20 \mu \mathrm{m}$ size limit.

Moreover, there are many examples of so-called "giant" sand-sized (> $63 \mu \mathrm{m}$ ) mineral particles collected more than 5,000 $\mathrm{km}$ away from their source. For example, quartz particles originating from the Asian

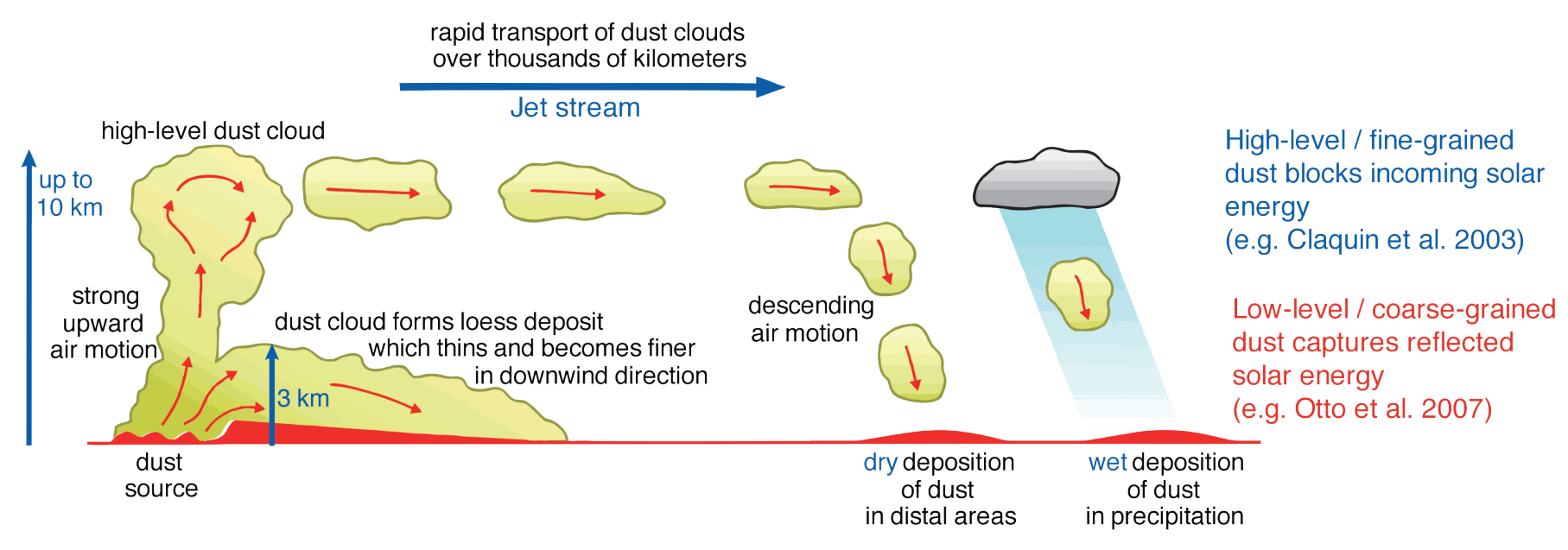

Figure 1: Schematic diagram showing different dust-transport mechanisms in the high- and low-level atmosphere (redrawn from Pye and Zhou 1989). 


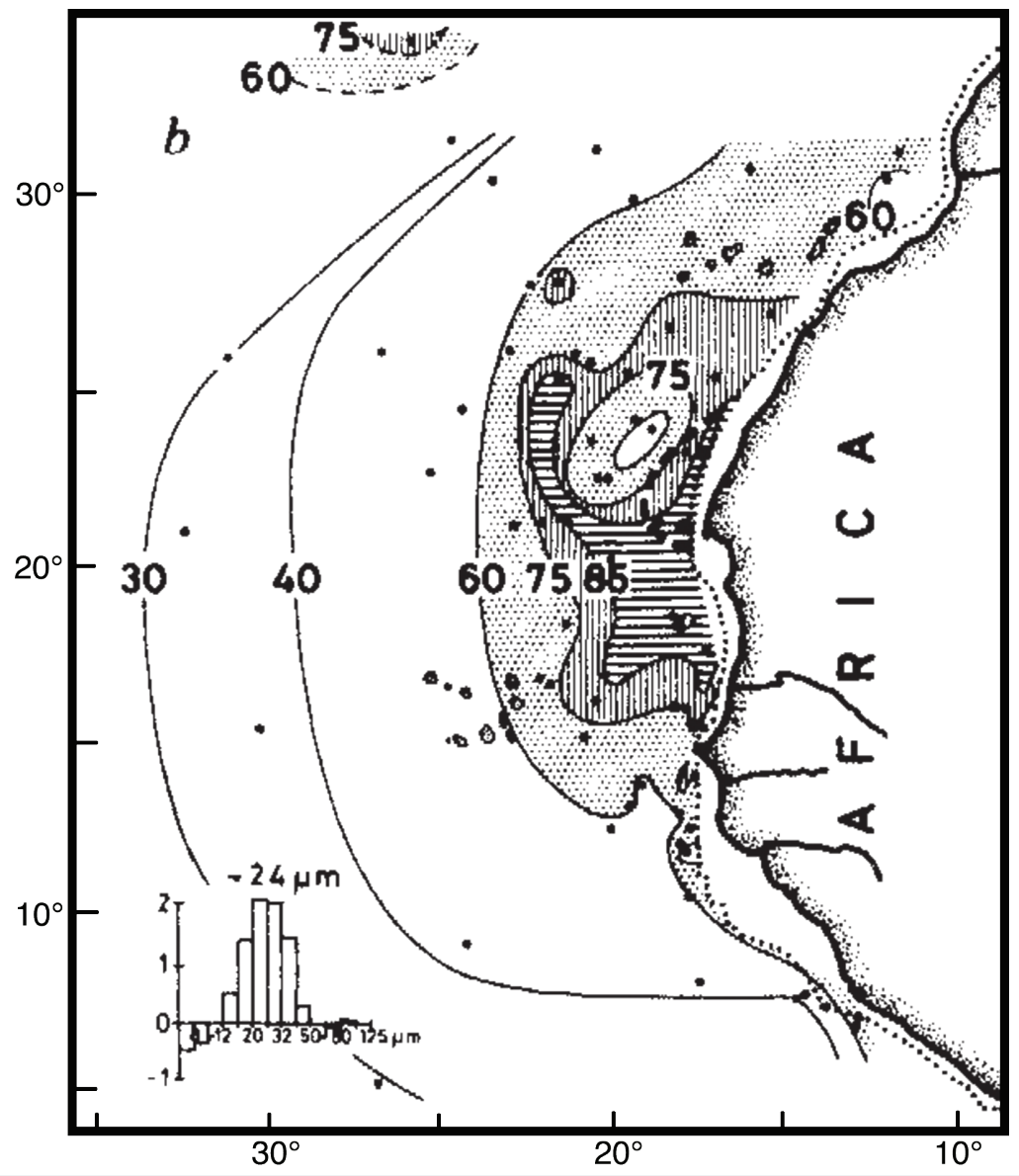

Figure 2: Map of the subtropical northeastern Atlantic, showing the decrease in both particle size and dust flux as measured in surface sediments by Sarnthein et al. (1981).

deserts were collected on Hawaii (Betzer et al. 1988), Asian-dust particles were collected in free-drifting sediment traps in the north Pacific (Middleton et al. 2001) volcanic particles were found in Greenland ice (Ram and Gayley 1991), and Saharandust particles were observed in high-volume dust collectors over the distal Atlantic ocean (Stuut et al. 2005). New unpublished results from transatlantic Saharan dust-monitoring projects (e.g. SALTRACE and DUSTTRAFFIC) show how large ( $>20$ $\mu \mathrm{m})$ Saharan-dust particles are observed suspended in the atmosphere, as well as deposited in moored marine sediment traps at thousands of kilometers from the African coast.

These observations suggest that the assumptions regarding the transport capacity of individual dust outbreaks need to be revised (e.g. Menéndez et al. 2014). Such revisions would have consequences not only for the interpretation of the proxy records, but also for the quantification of the climate-forcing effect of wind-blown particles in the atmosphere (e.g. Boucher et al. 2013)

\section{Marine production and export}

The size and shape of aeolian particles and dust-transport processes may also have affected past atmospheric $\mathrm{CO}_{2}$ changes, due to the role that sinking dust particles may play in the biological carbon pump in the oceans. Martin and Fitzwater's (1988) famous Fe hypothesis predicts that during glacial periods more micro-nutrients were transported to the ocean by mineral-dust, which boosted the growth of marine phytoplankton and zooplankton. The increased primary productivity and its downward export sequestered additional $\mathrm{CO}_{2}$ from the atmosphere (see also Martinez-Garcia and Winckler, this issue). A crucial step in this process is the export of organic matter from the surface ocean to the sea floor. Many Fefertilization experiments were carried out as a consequence of the postulated Fe hypothesis (e.g. de Baar et al. 2005). They demonstrated that it is indeed possible to boost marine life with artificially added dissolved micro-nutrients, but that most of the generated organic tissue containing the sequestered $\mathrm{CO}_{2}$ is being recycled in the surface ocean layer. Here, the dust particles may play a crucial role by providing mineral ballast for the aggregation and sinking of the organic tissue. If this ballasting process is fast enough, there is less time for the organic tissue to be recycled and the export of organic matter becomes more efficient. The speed of the downward transport from surface to the deep ocean is directly related to the size of the dust particles that act as anchors for organic matter.

Intuitively, one would think there is an upper limit to size and potential scavenging; a brick would be too large and sink too fast to have a significant scavenging effect. However, given that the largest dust particles observed near the African coast are smaller than $200 \mu \mathrm{m}$ (e.g. Ratmeyer et al. 1999; Skonieczny et al. 2013; Stuut, unpublished data from a dust monitoring station in (wik, Mauritania) and thus still have a relatively slow sinking speed, we assume that there are no dust particles too large to have a ballasting effect.

From the above, we infer that the larg est ballasting and scavenging effect will take place at proximal deposition sites. Thus, even without adding nutrients to the ocean, mineral dust may increase the C-cycle by speeding up the export of organic material to the sea floor.

On the other hand, particle size and associated sinking speed also impacts the bio-availability of the dust-borne micro-nutrients; the faster the particles sink, the less time remains to mobilize the nutrients they carry. Therefore, at distal locations, where dust particles are small and the size-dependent specific surface area of the particles is high, the amount of nutrients per mass is much higher than at proximal sites. We speculate that there is an ideal source-to-sink distance where dust particles are large enough to have an optimal ballasting effect, but also small enough to have an optimal fertilizing effect.

\section{Outlook}

The aforementioned role of mineral-dust particles assumed all deposition to be the result of gravitational settling from the atmosphere. However, hardly anything is known about wet deposition of mineral dust. New observations (Prospero, pers. comm.) seem to indicate that fluxes of wet-deposited dust not only are larger than those of dry deposition but that these "wet" mineral-dust particles are also coarser grained. Transatlantic observation projects have been set up to shed light at source-to-sink variability at high temporal resolution. Next to the physical and chemical properties, also the temporal and spatial (micro-)biological effects on nutrient availability and scavenging need to be studied, as they may play a dominant role on the aforementioned physical processes.

\section{AFFILIATIONS}

${ }^{1} \mathrm{NIOZ}$ - Royal Netherlands Institute for Sea Research, Den Burg, the Netherlands

${ }^{2}$ MARUM - Center for Marine Environmental Sciences, Bremen University, Germany

${ }^{3}$ Earth Sciences, Vrije Universiteit Amsterdam, the Netherlands

CONTACT

Jan-Berend Stuut: Jan-Berend.Stuut@nioz.nl

\section{REFERENCES}

Full reference list under:

www.pages-igbp.org/products/magazine/ref2014_2.pdf Betzer PR et al. (1988) Nature 336: 568

Claquin T et al. (2003) Clim Dyn 20: 193-202

Martin JH, Fitzwater SE (1988) Nature 331: 341-343

Stuut J-BW et al. (2005) J Geophys Res 110, doi:10.1029/2004JD005161

Weltje GJ, Prins MA (2003) Sediment Geol 162: 39-62 